\title{
DỨcin
}

Technological University Dublin

ARROW@TU Dublin

\section{Grief, loss, and separation: Experiences of birth children of foster carers}

David Williams

Technological University Dublin, david.williams@tudublin.ie

Follow this and additional works at: https://arrow.tudublin.ie/aaschsslarts

Part of the Sociology Commons

\section{Recommended Citation}

Williams, D. Grief, loss, and separation: Experiences of birth children of foster carers. Child \& Family Social Work. 2017; 22: 1448- 1455. DOI: 10.1111/cfs.12366

This Article is brought to you for free and open access by the Social Sciences at ARROW@TU Dublin. It has been accepted for inclusion in Articles by an authorized administrator of ARROW@TU Dublin. For more information, please contact arrow.admin@tudublin.ie, aisling.coyne@tudublin.ie, gerard.connolly@tudublin.ie.

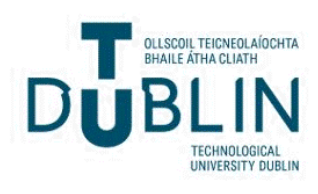




\section{Grief, loss, and separation: Experiences of birth children of foster carers}

\section{Dave Williams}

School of Languages, Law and Social Sciences, Dublin Institute of Technology, Dublin, Ireland Correspondence

Dr. Dave Williams, Room RD 105, School of Languages, Law and Social Sciences, Dublin Institute of Technology, Rathdown House, Grangegorman, Dublin, Ireland.

Email: david.williams@dit.ie

\begin{abstract}
Previous research identifies the increased exposure of birth children of foster carers to experiences of separation, grief, and loss due to the transient nature of foster care, but little is known about how birth children manage this loss. This paper reports findings from a qualitative study that examined the retrospective experiences of 15 adult birth children of foster carers (aged between 18 and 28 years) in Ireland. Findings suggest that birth children experience grief and loss when foster children leave their families. They report experiencing a range of emotional responses such as guilt, blame, and sadness. A reluctance to discuss their emotional responses with either their parents or foster care professionals was also reported. Instead, birth children developed strategies to manage the loss, such as distancing themselves from the foster care process. The study highlights the importance of social workers and foster carers explaining to birth children why foster children are leaving and, where possible, maintaining contact between birth children and foster children. Additionally, findings indicate the need for birth children to have safe nonjudgmental spaces to discuss their emotional reactions to loss.
\end{abstract}

\section{KEYWORDS}

birth children, foster care, grief, loss, social work

\section{1 | INTRODUCTION}

In Ireland, there has been a significant increase in the use of foster care placements for children who cannot live with their own families thus requiring alternative care. In 2000 , there were 5,517 children in care, with $66.3 \%(3,657)$ of those being placed in foster care. By the end of August 2016, the number of children in foster care rose to 5,920, representing $93.4 \%$ of children in care (Tusla, 2016). The foster care system in Ireland is governed by the Department of Children and Youth Affairs, with services being delivered by the Child and Family Agency (Tusla), the body responsible for the provision of child and family services. The Child Care Act, 1991 is the governing legislation, and foster care services are regulated by The National Standards for Foster Care, Department of Health and Children 2003, which outlines the rights of foster children, quality of care, and the duties of Tusla.

Although studies on the topic of foster care have increased (Goodyer, 2011; Staines, Farmer, \& Selwyn, 2011), relatively little research has documented the experiences of birth children in foster families (Hojer, Sebba, \& Luke, 2013; Younes \& Harp, 2007). A key issue that has arisen in research examining birth children's experiences is the subject of grief and loss (Nuske, 2010; Targowska, Teather, \& Cavazzi, 2013). Bourguignon and Watson (1987) recognise loss as the emotional state experienced by individuals when someone of significance is withdrawn, with grief being a natural response to loss (Fahlberg, 1994). For the purpose of this paper, the term grief and loss are used consistently throughout, as birth children in this study spoke of the loss and grief for the loss when foster children left their families. Existing literature in relation to birth children's experiences of loss arising from their involvement in foster care will now be examined. The research design and findings will also be outlined before the discussion arising from the conduction of this study exploring the retrospective experiences of 15 birth children of foster carers.

The experience of loss has been discussed in relation to birth children of foster carers with regard to loss of parental time and space (Part, 1993; Pugh, 1996; Watson \& Jones, 2002) and loss of innocence due to the exposure of the challenging behaviour and experiences of their foster siblings (Hojer, 2007; Pugh, 1996). Twigg and Swan (2007) suggest that loss of parental attention experienced by birth children is comparable to family situations where a new younger sibling is introduced. However, within foster care, this is more 
complicated for birth children as the change is often continuous, with the entry and exit of foster children; therefore, there is a continuous reorganisation of the family unit (Thompson \& McPherson, 2011). It has also been argued that the experience of loss when a foster placement ends is most difficult for birth children (Hojer et al., 2013; Irwin, 2005). This is further complicated by multiple experiences of loss with the entry and exit of foster children (Targowska et al., 2013), although little is known about how this loss is managed.

The impact of loss on birth children when foster children leave is referred to in some early research of birth children of foster carers (Ellis, 1972; Wilkes, 1974). Ellis (1972) identified the concerns of Canadian foster carers about the effects of foster children moving in and out on their own children. This was expanded upon by Kaplan (1988), who in his study of 15 birth children of foster carers, identified grief and loss as a significant issue due to the often temporary nature of fostering. Poland and Groze's (1993) survey of 51 birth children, $40 \%(n=20)$ identified dealing with grief and loss when foster children leave as an important issue to be discussed with birth children prior to fostering.

Irwin (2005) in her comparative study, including twenty birth children of foster carers (aged between 12 and 16 years) and 20 young people (aged between 12 and 16 years) from nonfostering backgrounds, discovered that those who fostered had more distressing experiences of trauma, loss, and separation due to foster children entering and exiting their lives. Birth children in foster families often build a strong bond with foster children regarding them as siblings; therefore, the loss and grief felt when foster siblings leave can be significant but is often discounted by adults (Walsh \& Campbell, 2010). Birth children having support from parents and professionals, following placement endings, is identified as an important element of birth children integrating experiences of grief and loss more positively (Sutton \& Stack, 2013).

In discussing supports for birth children, Hojer et al. (2013) highlight the importance of birth children being allowed to openly discuss with parents the problems arising from foster care, although the value of foster carers identifying protected time for their own children is also recognised as a key form of support in helping birth children manage the challenges raised by foster care (Walsh \& Campbell, 2010). Hojer et al. (2013) recommend the importance of training for birth children that prepares them realistically for the positive and negative aspects of fostering such as placement endings. The inclusion of birth children with experience of foster care in the delivery of this training is identified as an important feature of any such training (Hojer et al., 2013; Watson \& Jones, 2002).

Although existing research has identified the grief and loss experienced by birth children when foster siblings leave and recommends the need for birth children being supported, it has not focused on how they manage these experiences and the strategies they use to cope with this loss. The aim of this paper is to explore how birth children manage experiences of grief and loss related to the departure of foster children from their lives. This study provides insight into the techniques used by birth children to cope with grief and loss as well as documenting factors that influenced their management of loss. On the basis of the findings, recommendations are made in relation to supporting them through these experiences.

\section{2 | METHOD}

\section{1 | Design}

In line with accepting the individual experiences of the birth children, an interpretivist approach was adopted "as it implies a direct concern with experience as it is lived or felt or undergone" (Sherman \& Webb, 1988 , p. 7) and allows for understanding of how the world is constructed for participants (McLeod, 2001, p. 20). In accordance with this approach, semistructured interviews were conducted with 15 adult birth children of foster carers to document their retrospective experiences of foster care. The use of semistructured interviews permitted a degree of structure to collect data to address the research questions, whilst also providing flexibility in exploring participants' experiences.

The findings reported here are part of a larger doctoral study completed in 2015, which examined birth children's experiences of foster care. This paper focuses on birth children's experiences of grief and loss and relates to two research questions:

- What are the benefits and challenges of fostering for birth children in foster families? The participants were asked to describe the benefits and challenges that foster care had brought to their lives. They were not prompted except to clarify points, in order to capture the elements that they found to be the most beneficial and most challenging elements of foster care. During discussions on the challenges of fostering, participants reported grief and loss as one of the most challenging factors, particularly in relation to the feelings arising from the departure of foster children. This is elaborated upon further in the findings section.

- What are the training and support needs of birth children in foster families? On the basis of their experiences of foster care, the participants were asked to explain how birth children might be best prepared and supported in the foster care process. During the discussions on the support needs of birth children, participants made suggestions on how birth children in foster families might be better supported to deal with the grief and loss experienced when foster children leave their homes.

\section{2 | Procedure}

The age criteria for the study was set between 18 and 30 years of age, whereas a criteria of parents fostering not longer than 3 years ago was also set to ensure that participants' fostering experiences were recent. Participants included in the study were aged between 18 and 28 years, with a mean age of 23.3 years (SD 3.3 years). The number of children fostered by each participant's family varied from between one child and 46 foster children, with the mean number of children fostered being 23.6 (SD 16.9 children). The age of the participants when their families began to foster varied from before a participant was born to 14 years of age, with a mean age of 9.46 years (SD 3.8 years). Of the 15 birth children included in the study, seven still lived with their parents.

The study was advertised through the Irish Foster Care Association via their quarterly newsletter. This invited eligible 
individuals to volunteer to partake in the research. Two birth children who met the eligibility criteria were also purposively chosen. These were professional acquaintances of the researcher. The recruitment strategy for the study, including the purposive sample of the professional acquaintances, was detailed in the application for ethical approval and was granted. There were no differences in the reported experiences of these two participants to that of the others in the study. All interviews were digitally recorded and varied in length from 50 to $70 \mathrm{~min}$.

\section{3 | Ethics}

Ethical approval for the study was granted by the Social Research Ethics Committee at University College Cork. Each participant was e-mailed a consent form and a copy of the interview schedule prior to interview. At interview, they were reminded of their rights to confidentiality and anonymity and the consent form was revisited. Each participant was assigned a pseudonym, and this is used in the findings.

\section{4 | Data analysis}

Braun and Clarke's (2006) framework for thematic analysis guided analysis of the dataset. This involved first reading and rereading the data and noting down initial ideas. Potential themes were then classified from the initial codes generated. Through further analysis, themes were refined and titled in relation to the research questions and existing literature. This led to the identification of three themes relevant to participants' experiences of loss. These were participants' experiences of grief and loss, strategies used to manage grief and loss, and the support needs for birth children in managing grief and loss.

\section{3 | FINDINGS}

Although participants spoke of their experiences of grief and loss, 12 of the 15 birth children in this study identified foster care as a positive in their lives, reporting that it made them more compassionate, caring, and nonjudgmental people:

Through fostering I got a very different view of the world. It opened my eyes up to a world I would have never seen. I think it was a beneficial education and I am a more open minded person because of it and I am glad I am the person I am.

[Keith]

I think overall fostering has been positive. A lot of the traits I have, I'm generous, caring, empathetic, patient are definitely due to foster care.

[Karen]

However, participants also stated that these experiences came at a cost, identifying grief and loss as one of the most challenging elements of foster care, which, if managed better, would have helped them have more positive foster care experiences:
Overall foster care has been a positive and it has helped make me who I am, a caring, thoughtful person. Then again, the whole idea of loss is big and I have this, how much do you give of yourself to somebody, and are they just going to go away; I grew up with that.

[Rebecca]

\section{1 | Birth children's experiences of grief and loss}

All participants spoke about the issue of grief and loss when foster children leave. Several compared this loss to a family bereavement:

You can't foster and not get emotionally involved. You can't foster and not get attached to people living in your house; you're going to love them. You're going to be upset when they leave ... it's like someone dying. [Winnie]

A big struggle for me was that we had loads of different kids come to us and leave and I don't think a social worker or anybody asked about how I was affected by it all.

[Rebecca]

Avril commented that although parents and professionals comprehend the reasons why foster children are moved, birth children may not understand and nothing is explained to them, despite the close relationships that they may have built with foster children:

A big thing is the issue of children leaving, the adults know about the whole thing but children don't understand children coming and going. You're told they're not your real sister or brother, but they are, they become part of the family. I think the grief and loss for the biological child is a big thing and families just move onto the next placement, so that's one thing that needs to be dealt with better.

[Avril]

This was raised by other participants who emphasised the importance of parents and professionals explaining to children why foster children are leaving:

Talk to us and tell us what's going on. Explain why you are taking these kids back, why you are moving kids to other houses. Then, when the kids go, let us visit them ... this kid has been your brother or sister.

[Winnie]

It's a difficult thing to think about, losing a sibling and I think it's one of those things about foster care, you get attached to your foster siblings and it's always difficult when they leave. If there was more transparency social workers, parents and biological children could talk more openly, that would help.

[Sandra] 
Eight participants spoke about feelings of guilt that they experienced when some foster children left, as they recognised the children came from difficult situations, but they were relieved when the placements ended. Tony identified this as the most negative aspect of his foster care experience:

You feel bad that you wanted some of the foster kids to go but realise how good you had it. I do feel a bit of guilt that I wanted them to go, although I shouldn't feel guilty because I was only a kid, but that is something that was a negative.

Avril also identified this as significant, "I definitely think there are issues around guilt. Not wanting a child there and feeling guilty about that especially when a child leaves." This too resonated with Rebecca who said "if someone had just sat me down and explained why a kid is leaving that would have been much better, I wouldn't have had the guilt thinking about that they left because of me or something I said."

Ten participants expressed upset at not being able to stay in contact with foster children once they moved to another placement. Participants emphasised the importance of allowing, where possible, contact to continue between foster children and foster families postplacement in order to help birth children deal with the loss of foster children:

When the kids go, let us visit them ... it would be good to be able to have a continued relationship between the foster kids and the biological kids, as some of the foster kids are there since they were toddlers so, for the birth kids, it's like a death in the family.

[Winnie]

A key finding of this study is not only the contradictory feelings reported by some birth children when placements end, as they may mourn the loss of a foster child, but also, in another sense, be relieved that the child is gone, thus leading to feelings of guilt and blame. This indicates the importance of parents and professionals explaining the reasons for placement endings to birth children, so they do not carry this sense of blame and guilt.

Several participants also emphasised that, aside from it being beneficial for the birth children to maintain contact after placements, it would also benefit the foster children as they learn to understand why they had to leave a particular foster placement and also possibly maintain valuable relationships in their lives:

For the girl that left us after 8 years it must have been terrible, to live with a family for so long and she thinks, after all that time, we didn't even try to contact her. [Avril]

\subsection{Strategies used by birth children to manage grief and loss}

Participants spoke about the lack of support provided to families following placement endings, with Greta stating, "social workers just gloss over it and expect you to take a new child in a few weeks."
Winnie highlighted the need for support in helping foster families recover from the grief and loss:

I was 16 when the foster child was moved; it would have been helpful to have someone to help us deal with it. We were just told to say goodbye to the child and that was it. Social workers could have helped us deal with the feelings, the grieving.

Participants also identified the strategies they utilised to protect themselves from this grief and loss. Rebecca stated that her experiences of loss made her reluctant to become too close to foster children for fear of them being taken away again. This was relevant for others in the study, who developed self-protection strategies in order to shield themselves from the emotional pain created by foster children entering and exiting their lives. Anita reported that she made a conscious choice not to become attached to foster children, after a young girl with whom she became close was moved to another placement:

The first girl I used to play with but then things changed and I didn't want anything to do with it anymore. We had the first girl for 4 years and then they decided to put her in another placement and I just cut myself off from the others because I didn't want to become close to other kids because they'd be gone.

[Anita]

This experience of grief and loss impacted upon how participants adapted to their family's fostering as time went on, with some clearly stating how they avoided becoming attached to foster children. Five participants identified the age of the children as also influencing the impact of the loss experienced, as it seemed to be more difficult for birth children when babies and younger children left as compared to teenagers:

When some of the kids left it was tough. When the older ones left it was easier but with the babies it would have been tough. I definitely would have cried a few times. When the two babies left, you try not to get as attached. After a while you tell yourself not to get as close. After the younger ones left I took a step back.

[Mary]

Aside from the grief and loss experienced by the birth children themselves, several participants spoke about witnessing the effect of children leaving on their own parents, primarily mothers. Tony explained that he became worried about how the continuous experiences of grief and loss affected his mother whom he said found it difficult when some of the children left. Heather discussed the influence of what she described as a "particularly traumatic placement breakdown" on her mother and expressed concern how this affected her, as this was the first time she saw her mother cry and become upset.

The participants identified ways they tried to protect their families from the challenges related to foster children leaving. In some cases, participants provided practical support to parents following foster children's departure. Mary spoke about the pressure she felt sometimes in supporting her mother because of the impact fostering had: 
I did feel pressure from fostering sometimes. Mam got really upset when one of the babies moved on so I used to come home from college to cook the dinner. That's one of the reasons I didn't move to [name of city] when going to college. I feel like I'd be like mam's little counsellor.

Five participants also spoke of the emotional support they provided as they acted as confidants for their mothers in dealings with some of the challenging elements of fostering, such as children leaving.

Some participants explained that they actively encouraged parents not to accept new foster placements, particularly after the ending of a placement where the family had a close relationship with the foster child:

When I was 15 or 16 I remember having arguments with my parents, I would give out to my parents for taking on too much and say "what are you doing, you know this is not healthy." They were talking about taking on a new foster child but my mam was still really upset about the last foster child who left.

[John]

Although some participants consciously took a step back from their involvement in fostering due to experiences of loss, some explained how they used birth siblings as a form of support:

My support would come from my birth siblings. I don't think you can get much support from your friends because they don't really know or understand it. No, I would have talked to my sisters particularly after a tough time where a foster kid you got close to moved. [Geraldine]

With your siblings you could say what you liked, when you liked and not feel like you were being judged. We were a comfort to each other and we could talk about the stuff that was tough, like when kids moved home or to another placement.

[Ann]

\section{3 | Training and support to help birth children manage grief and loss}

All participants believed training would help birth children prepare for foster children leaving and address some of the associated feelings:

Some training would have been nice and it would be good hear from others whose families had fostered. They never prepare you for when kids go. You have this baby that you have changed nappies for and cared for and then they're gone.

[Greta]

Anita explained that, "training could have helped us deal with the feelings, the grieving after the foster child left." Martina spoke about the lack of professional support for her and her sister, following a placement breakdown. Most birth children stressed the importance of birth children in foster families having someone to talk to as an important source of support. In some cases, parents and professionals did not know or acknowledge these issues, as they did not consult with birth children, or birth children did not feel comfortable in revealing their feelings.

Participants in some instances struggled with the fact that they had no one they could talk to, for a variety of reasons, including social workers not being available, not having a relationship with social workers, not wanting to upset or burden parents, or friends simply not understanding foster care:

My friends in college don't really understand my family set up so you don't really have somebody to talk to and for the biological children in foster families, that's what you need, just somebody to talk to.

[Mary]

Participants also emphasised the value in birth children getting an opportunity to speak and engage with their peers from other foster families who would be familiar with their issues. This might be best provided through a support group:

My parents went to the Foster Care Association meeting
and met with parents and heard their experiences but
we never met any of the kids from families who
fostered. It would be good if there was a youth club or
support group for kids and young people who foster.
Nothing too heavy, just informal meetings so you could
have a connection with someone who is in the business.
[Heather]

Two participants spoke of a support group founded in their area for birth children of foster carers when they were teenagers. They explained that the group was set up by a social worker interested in supporting birth children. Both found the group to be a positive experience. Tracey explained "the 'Young People whose Parents are Foster Parents' group ran for a year. It was really good at the time." Geraldine emphasised that having a safe place to talk openly about issues and feelings related to foster care was a real benefit:

That support group and I know we only met a couple of times, but it was brilliant, it was hugely beneficial. It was just so open. We were all sitting in a circle and you were able to tell your story but it was positive and a safe place to get out whatever was there.

Others believed it might be beneficial to have a support helpline for birth children:

I think having someone to ring or talk to would have been helpful, especially when some of the children left. It would have been helpful if I had have been able to ask someone questions about fostering other than my parents.

[John] 
We wouldn't have known who the best person to talk to was but maybe a youth worker, even if they were on the end of phone from Monday to Friday. It would have helped if you could ring up and ask a simple question. [Karen]

\section{4 | DISCUSSION}

\section{1 | Birth children's' experiences of grief and loss}

Previous research (Part, 1993; Pugh, 1996; Watson \& Jones, 2002) have focused on loss of parental attention and loss of possessions or personal space as significant, particularly for younger birth children in foster families. This research, however, reports that participants were less concerned with this element of loss but more with experiences related to grief and loss following the departure of foster children. This may be attributed to the age of participants, who, perhaps through the distance of time, were capable of making more mature and insightful reflections on their experiences.

Although it must be recognised that foster care is a complex process involving the interests of a number of different stakeholders (Sinclair, Wilson, \& Gibbs, 2005), these findings suggest the importance of parents and professionals not underestimating the effect of foster children leaving on birth children in foster families. Although previous research (Hojer, 2007; Sutton \& Stack, 2013) have emphasised the importance of open and honest communication to allow birth children feel like valued members of fostering teams, this study specifically suggests the benefit of parents and professionals speaking to birth children after placement endings, to explain the reasons why foster children are moving.

One of the reported factors that contributed to birth children's experience of loss was parents and professionals not explaining when and why foster children were leaving. This contributed to the sense of loss, confusion and, in some cases, feelings of guilt as to why foster children had to leave. This study indicates the value of explaining this to birth children and also, where possible, maintaining contact between foster families and foster children, as it may help relieve some of the mixed emotions birth children may have in relation to placement endings. Although it is also important to recognise that birth children are not professiona carers, thus, a distinction must be made between informing and supporting them but not overburdening them with adult responsibility.

Previous research (Targowska et al., 2013) indicates that the repeated experiences of children leaving lessened birth children's feelings of grief and loss when further foster children departed. However, this study contends that, even as adults, participants still recall the difficult emotions and issues arising from foster children leaving their lives and provides suggestions from those who experienced these emotions about how birth children can be supported to have more positive experiences of foster care.

\subsection{Strategies used by birth children to manage grief and loss}

Literature has identified the practical tasks undertaken by birth children in the foster care process (Hojer, 2007; Younes \& Harp,
2007); however, this study highlights the emotional work they also undertake, particularly in relation to their families' experiences of loss. Birth children in foster families played an important role in providing emotional support to parents and sometimes siblings, when foster children leave. Birth children recognised the toll that such incidents placed on their parents and, subsequently, attempted to support them emotionally as well as practically. This was clearly identified by the participant in this study who referred to herself as "mam's little counsellor." However, it is somewhat concerning that, in attempting to support their parents, birth children often neglected their own emotional needs, as they did not disclose concerns or worries to parents for fear of placing burden on them. Instead, they developed their own coping strategies in order to manage their experiences of grief and loss. Some birth children stated that sometimes their parents took on too much responsibility and accepted placements too soon, although still grieving for a departed foster child.

Previous research has ascertained the increased exposure of birth children to incidents of grief and loss, when compared to their nonfostering peers (Irwin, 2005; Walsh \& Campbell, 2010). A finding absent in existing literature relates to how this grief and loss is managed. This study identifies some of the techniques used by birth children to manage their experiences of loss, as well as outlining how they attempted to support their families through this challenging element of foster care. Although birth children made attempts to protect themselves amidst the challenges brought about by foster care, the management of the issue of grief and loss was not easy, and it was also apparent that not all the needs of the birth children were resolved. This was evident when they spoke about the limited support they had in dealing with issues arising from foster children leaving.

\subsection{Training and support to help birth children manage grief and loss}

Although the importance of providing training and support to birth children in managing the grief and loss brought about by fostering has been identified (Hojer et al., 2013; Walsh \& Campbell, 2010), the views of birth children, in relation to their direct support needs in managing this loss, is limited. This study, through drawing on the experiences of participants, outlines suggestions as to how birth children might be practically supported, particularly in relation to dealing with experiences of grief and loss following placement endings. As retrospective informants, the majority of participants identified foster care as a positive in their lives; however, they also clearly acknowledged the ambiguity they felt in relation to some elements of foster care and the feelings it brought with it, such as grief, guilt, and jealousy.

\section{5 | LIMITATIONS}

Using a retrospective approach, although not without limitation, offered advantages in allowing birth children in this study discuss candidly their experiences of foster care. As reported by Hardt \& Rutter (2004, p. 261), a limitation of contemporaneous research studies can be "... some 'hidden' experiences are unlikely to be reported contemporaneously in childhood." Although a critique of 
retrospective studies is that the data collected may be somewhat inaccurate as subjects "view the past through the lens of the present" (Silverman, 2010, p. 192), de Graffe \& Rademakers (2011, p. 125) contend that

The most important advantage of retrospective studies is that cognitive abilities of the respondents are sufficiently developed for them to answer (fairly) complicated questions. Furthermore, retrospective research gives the researcher the opportunity to investigate recalled cognitions or emotions.

Some findings presented here are similar to findings from existing research from other countries. This suggests that the findings of this research may be relevant to the wider population of birth children of foster carers, both nationally and internationally. However, because this research adopted a retrospective approach, it is possible that the findings are due to the mature reflection and articulation abilities of the participants, rather than location.

This paper highlights the value of gathering the perspectives of adult birth children of foster carers, although, the possible limitations of the data sample should be acknowledged. The sample is a volunteer sample and, hence, susceptible to sample bias, with some participants possibly volunteering to partake in the study to voice their frustrations with the foster care system. However, some of the findings presented here also identify birth children participants discussing positive elements of fostering, such as foster care making them more caring, resilient, and compassionate individuals. Due to the small sample size, the findings of this study cannot be deemed to be representative of the wider population of birth children, although there is evident similarity between some of the findings with those of other studies, although there is significant elaboration on ambivalent feelings, coping strategies, and types of support.

\section{6 | IMPLICATIONS FOR PRACTICE}

The findings of this study highlight the importance of parents and professionals not underestimating the effects of grief and loss on birth children when foster children leave. Findings also indicate the importance of birth children being provided with opportunities for their feelings of grief and loss to be acknowledged. Foster carers, during their assessment and training, should be reminded of the possible impact of continuous experiences of loss brought about by foster care on both themselves and their own children. They should be reminded of the value of allowing time, after the departure of a foster child, for all family members to grieve and mourn as required, before agreeing to new placements. Social workers should also be cognisant of this matter and, where possible, refrain from placing a new child with a family who may be still recovering from the loss of a foster child.

This study also stresses the value of birth children understanding the reasons why foster children are departing, to help alleviate any mixed emotions they may hold about the event. Social workers also, where feasible, might support opportunities where foster families could maintain contact with former foster children. This may be beneficial to all parties in managing the mourning process following placement endings.

The importance of training and support being provided to birth children is also evident. This would help them manage the complex and often contradictory emotions related to placement endings. It would seem that often, birth children are left to manage these feelings alone, and in some cases, act as support figures to parents and/or siblings dealing with the loss of foster children. Training would provide a valuable opportunity for children, whose families have just begun fostering, to hear from birth children with more experience of the fostering process, in terms of what to expect from foster care, and advice on dealing with experiences of grief and loss following the departure of foster children.

A key finding from this study relates to the needs for birth children to have a nonjudgemental space outside of their immediate family, where they can express their views and feelings regarding the loss of foster siblings. Participants suggested the value of birth children being able to meet with other children whose families foster, as often their nonfostering peers do not fully understand their specialised family life circumstances. Although it seems that previous attempts have been made in Ireland to develop support groups for birth children in foster families, this has been done in an inconsistent and ad hoc manner, thus, suggesting the importance of the stakeholders in the Irish foster care system recognising the value of such interventions as a consistent form of support to birth children in foster families.

In the United Kingdom, the Fostering Network have published a guide book "Don't You Forget About Me: A Guide to Developing a Peer Support Group for the Sons and Daughters of Foster Carers" to help fostering agencies develop support groups for birth children. These groups might be piloted in a small number of areas and, if successful, be developed in several social work areas nationally. Previous research highlights the links between placement breakdown and the negative impact of foster care on birth children, in some cases leading to foster carers ceasing to foster (Briggs \& Broadhurst, 2005; Kalland \& Sinkkonen, 2001; Quinton, Rushton, Dance, \& Mayes, 1998; Thompson \& McPherson, 2011); these groups would not only be valuable in supporting and giving a voice to the perspectives of birth children but might also contribute to the overall wellbeing of foster families.

In conclusion, this research indicates that birth children in foster families experience ambivalent emotions associated with the loss of foster siblings and need a safe and understanding space in which to express these emotions, following the departure of a foster sibling, although it also suggests a potential role for both parents and professionals in supporting birth children through this often challenging and complex experience.

\section{REFERENCES}

Bourguignon, J. P., \& Watson, K. W. (1987). After adoption: A manual for professionals working with adoptive families. Springfeild, Illinois: Department of Children and Family Services.

Braun, V., \& Clarke, V. (2006). Using thematic analysis in psychology. Qualitative Research in Psychology, 3, 77-101.

Briggs, F., \& Broadhurst, D. (2005). The abuse of foster carers in Australia. Journal of Economics Institute of Australia, 12(1), 25-35.

Child Care Act. (1991). Dublin: Stationery office. 
De Graffe, H., \& Rademakers, J. (2011). The psychological measurement of childhood sexual development in Western societies: Methodological challenges. Journal of Sex Research, 48(2-3), 118-129.

Department of Health and Children (2003). National standards for foster care. Dublin: Stationery Office.

Ellis, L. (1972). Sharing parents with strangers: The role of the group home foster family's own children. Child Welfare, 51(3), 165-170.

Fahlberg, V. (1994). A child's journey through placement (2nd ed.). London: British Agency for Adoption and Fostering.

Goodyer, A. (2011). Child-centred foster care: A rights-based model for practice. London: Jessica Kingsley Publishers.

Hardt, J., \& Rutter, M. (2004). Validity of adult retrospective reports of adverse childhood experiences: Review of the evidence. Journal of Child Psychology and Psychiatry, 45(2), 260-273.

Hojer, I. (2007). Sons and daughters of foster carers and the impact of fostering on their everyday life. Child and Family Social Work, 12(1), 73-83.

Hojer, I., Sebba, J., \& Luke, N. (2013). An international literature review of the impact of fostering on foster carers' children. Oxford: Rees Centre, University of Oxford.

Irwin, B. (2005). The impact of the temporary nature of foster care on the birth children of foster carers. Unpublished MSc. Thesis, Trinity College Dublin, Ireland.

Kalland, M., \& Sinkkonen, J. (2001). Finnish children in foster care: Evaluating the breakdown of long term placements. Child Welfare: Journal of Policy, Practice and Program, 80(5), 513-527.

Kaplan, C. (1988). The biological children of foster parents in the foster family. Child and Adolescent Social Work, 5(4), 281-299.

McLeod, J. (2001). Qualitative research in counselling and psychotherapy. London: Sage.

Nuske, E. (2010). Balancing contradictions: The experiences of the biological children of foster families. Children Australia, 35(3), 32-39.

Part, D. (1993). Fostering as seen by the carers' children. Adoption and Fostering, 17(1), 26-31.

Poland, D., \& Groze, V. (1993). The effects of foster care on biological children in the home. Child and Adolescent Social Work Journal, 10(2), 153-163.

Pugh, G. (1996). Seen but not heard? Addressing the needs of children who foster. Adoption and Fostering, 19(1), 35-41.

Quinton, D., Rushton, A., Dance, C., \& Mayes, D. (1998). Joining new families. Chicester: Wiley.
Sherman, R. R., \& Webb, R. B. (1988). Qualitative research in education: a focus. In R. R. Sherman, \& R. B. Webb (Eds.), Qualitative research in education: Focus and methods (pp. 2-21). Bristol: Falmer Press.

Silverman, D. (2010). Doing qualitative research (3rd ed.). London: Sage.

Sinclair, I., Wilson, K., \& Gibbs, I. (2005). Foster placements: Why they succeed and why they fail. London: Jessica Kingsley.

Staines, J., Farmer, E., \& Selwyn, J. (2011). Implementing a therapeutic team parenting approach to fostering: The experiences of one independent foster-care agency. British Journal of Social Work, 41, 314-332.

Sutton, L., \& Stack, N. (2013). Hearing quiet voices: Biological children's experiences of fostering. British Journal of Social Work, 43(3), 596-612.

Targowska, A., Teather, S., \& Cavazzi, T. (2013). Supporting the children and young people of foster carers. Perth: Edith Cowan University.

Thompson, H., \& McPherson, S. (2011). The experience of living with a foster sibling, as described by the birth children of foster carers: A thematic analysis of the literature. Adoption and Fostering, 35(2), 49-60.

Tusla (2016). Monthly management data activity report august 2016. Available at http://www.tusla.ie/uploads/content/Tusla_Management_ Data_Report_August_2016_.pdf. [Accessed 15 ${ }^{\text {th }}$ December 2016].

Twigg, R., \& Swan, T. (2007). Inside the foster family: What research tells us about the experiences of foster carers' children. Adoption and Fostering, 8(4), 49-60.

Walsh, J. \& Campbell, H. (2010) To what extent does current policy and practice pay adequate attention to the needs of the sons and daughters of foster carers, particularly in the context of planned or unplanned placement endings? Report for Children's Workforce Development Council, Leeds.

Watson, A., \& Jones, D. (2002). The impact of fostering on foster carers' own children. Adoption and Fostering, 26(1), 49-55.

Wilkes, J. R. (1974). The impact of fostering on the foster family. Child Welfare, 53(6), 373-379.

Younes, M. A., \& Harp, M. (2007). Addressing the impact of foster care on biological children and their families. Child Welfare, 86(4), 21-40.

How to cite this article: Williams D. Grief, loss, and separation: Experiences of birth children of foster carers. Child \& Family Social Work. 2017;22:1448-1455. https://doi.org/ $10.1111 /$ cfs.12366 